\title{
Spontaneous bilateral femoral neck fracture in a man with end-stage renal disease and severe secondary hyperparathyroidism
}

\author{
Soraya Doustmohamadian, Majid Foroutan*
}

\begin{abstract}
Medical treatment is the primary recommended method for in the management of severe secondary hyperparathyroidism (SHPT) in pre-dialysis individuals. This paper reports a case of end-stage renal disease (ESRD) and severe SHPT with pathologic bilateral hip fractures. A 61-year-old man, as a known case of ESRD, with radial osteoporosis and persistent SHPT ( intact PTH $>2000$ pg/ $\mathrm{mL}$ ) and hypercalcemia with appropriate level of phosphorus and $25(\mathrm{OH}) \mathrm{D}$ who did not respond to medical treatment referred to hospital with multiple fractures. The patient referred for subtotal parathyroidectomy. One month after parathyroidectomy, parathyroid hormone (PTH) level significantly diminished from its preoperative values. Serum calcium and phosphorus returned to normal values and muscle weakness progressively improved until the patient became able to walk again. Parathyroidectomy in patients with severe secondary hyperparathyroidism (persistent serum levels of intact PTH $>800 \mathrm{pg} / \mathrm{mL}$ ) is suggested, particularly when is associated with severe hypercalcemia and/or hyperphosphatemia, and progressive and debilitating hyperparathyroidism bone disease, that are refractory and resistant to medical therapy.

Keywords: Secondary hyperparathyroidism, Chronic kidney disease, End-stage renal disease, Hypercalcemia, Cardiovascular disease, Tertiary hyperparathyroidism, Parathyroidectomy

Please cite this paper as: Doustmohamadian S, Foroutan M. Spontaneous bilateral femoral neck fracture in a man with end-stage renal disease and severe secondary hyperparathyroidism. J Parathyr Dis. 2017;5(2):42-44. DOI: 10.15171/jpd.2017.04.

Copyright $\odot 2017$ The Author(s); Published by Nickan Research Institute. This is an open-access article distributed under the terms of the Creative Commons Attribution License, which permits unrestricted use, distribution, and reproduction in any medium, provided the original work is properly cited.
\end{abstract}

\section{Introduction}

Secondary hyperparathyroidism (SHPT) is a common outcome of the natural progression of chronic kidney disease (CKD), particularly presented when glomerular filtration rate (GFR) drops to $<80 \mathrm{~mL} / \mathrm{min} / 1.73 \mathrm{~m}^{2}$ for more than three months (1). SHPT and abnormal mineral metabolism are thought to have an important role in bone and cardiovascular disease (CVD) in patients with CKD or end-stage renal disease (ESRD) (2). Severe SHPT may lead to pruritus, deterioration of residual renal function, calciphylaxis, CVD, neuromuscular disturbances, and death (3).

Medical therapy is the initial treatment for managing severe SHPT in pre-dialysis patients (4). Numerous studies and guidelines suggest parathyroidectomy for refractory medical therapy in severe SHPT $(5,6)$. However, there is no documented definition for refractory cases.

Given the effect of severe hyperparathyroidism on bone, heart, morbidity, and mortality, and because of inconsistency in treatment methods especially for diagnosis of parathyroidectomy in chronic kidney patients with severe hyperparathyroidism, we decided to report a case of ESRD and severe SHPT with pathologic bilateral hip fractures. We also discussed the treatments of hyperparathyroidism in ESRD patients.

\section{Case Presentation}

A 61-year-old man, as a known case of ESRD for 11 years with unknown etiology who was under hemodialysis three times a week, referred to the hospital with multiple fractures in right knee and fifth, sixth, seventh anterior ribs in the left side. Patient was under treatment of calcitriol $0.25 \mathrm{mg}$ two times daily, tablets of calcium carbonate 500 $\mathrm{mg} /$ four times a day, and sub-cutaneous erythropoietin three times a week.

He had recently referred for severe and sudden right pelvic pain, without a history of trauma. Pelvic X-ray showed a bilateral non-traumatic hip fracture that had been treated by hip replacement.

In physical examination, he had ash-colored dry skin with scratch marks, hyper-pigmented papules over the scapular area, pale palpebral conjunctivae, thoracic kyphosis, globular abdomen, arteriole-venous $(\mathrm{A}-\mathrm{V})$ shunt on the left arm and decreased range of motion in right shoulder, painful active and passive motion of knees, and also a bipedal edema. 
Implication for health policy/practice/research/ medical education

Parathyroidectomy is suggested in patients with severe secondary hyperparathyroidism (persistent serum levels of intact PTH> $800 \mathrm{pg} / \mathrm{mL}$ ) is suggested particularly when it is associated with severe hypercalcemia and/ or hyperphosphatemia with progressive and debilitating hyperparathyroidism bone disease, that is usually refractory and resistant to medical therapy.

To investigate the causes of multiple pathologic fractures, various para-clinical analysis were conducted. According to laboratory data, serum calcium was $10.8 \mathrm{mg} / \mathrm{dL}$ (8.510.5), phosphorus was $4.5 \mathrm{mg} / \mathrm{dL}$, and albumin value was $3.6 \mathrm{~g} / \mathrm{dL}$ (3.5-5). Additionally, serum alkaline phosphate was $2495 \mathrm{IU} / \mathrm{L}$, serum 25(OH)D3 was $24 \mathrm{ng} / \mathrm{mL}$ (30-50 $\mathrm{ng} / \mathrm{mL}$ ), and finally intact parathyroid hormone (iPTH) was $2281 \mathrm{pg} / \mathrm{mL}$ (normal values: 15-65 pg/mL). Since hypercalcemia was mild, calcium carbonate ( $\mathrm{CaCo} 3)$ was discontinued. Several weeks after discontinuing $\mathrm{CaCo3}$, the laboratory test was repeated and serum calcium level was $10.5 \mathrm{mg} / \mathrm{dL}$, serum phosphorus level was $4 \mathrm{mg} / \mathrm{dL}$, and serum alkaline phosphate level was $2514 \mathrm{IU} / \mathrm{L}$ and also serum iPTH level was $2500 \mathrm{pg} / \mathrm{mL}$. Around one month after hip replacement, a bone mineral densitometry (BMD) was conducted. It detected low density in cortical bone due to SHPT. The results of T-scores were as follows: (Lumbar Spine) T-score $=-1.4, \mathrm{Z}$-score $=-0.7$

(Fore Arm) T-score $=-6.7, \mathrm{Z}$-score $=-5.8$

In imaging study, renal sonography showed several stones (5-15 mm) in both kidneys. In echocardiography, patient had left ventricular ejection fraction of $50 \%$. Additionally, mild MR and TR were observed. The patient had several lytic lesions with decreased bone density in pelvic $\mathrm{X}$-ray, rotator cuff calcific tendonitis in shoulder X-ray, and rugger jersey spine in thoracolumbar X-ray (Figure $1 \mathrm{~A}, \mathrm{~B})$.

According to the persistence of severe SHPT and hypercalcemia and while the patient did not respond to medical treatment after several months, he referred for subtotal-parathyroidectomy. Around 3/5 of parathyroid glands were removed. Nodular parathyroid hyperplasia was the result of pathology report (Figure 2).

One month after parathyroidectomy, the laboratory tests showed a significant reduction in parathormone,

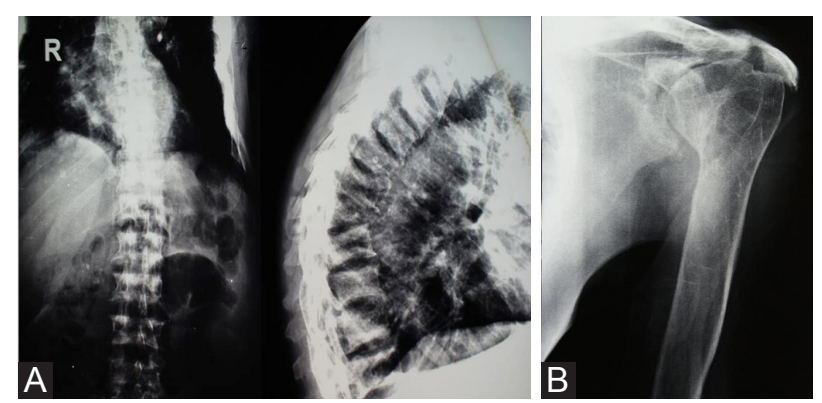

Figure 1. A; Rugger jersey spine in thoracolumbar X-ray. B; rotator cuff (calcific tendonitis) in shoulder X- ray. as compared with preoperative values. Serum calcium returned to normal level (Ca; $8.2 \mathrm{mg} / \mathrm{dL}, \mathrm{P} ; 4 \mathrm{mg} / \mathrm{dL}$, Alp; 1910 IU/L, iPTH; 190 pg/ml) too. Additionally, bone pain symptoms and muscle weakness progressively improved until the patient had became able to walk again.

\section{Discussion}

Initial treatment for managing SHPT in pre-dialysis individuals is the management of hyperphosphatemia, first initiated with limiting phosphorus diet. Although optimal limit of phosphate is unclear, $900 \mathrm{mg} / \mathrm{d}$ is suggested. If hyperphosphatemia does not improve by diet restriction, then calcium carbonate or non-calcium phosphate binders (based on serum $\mathrm{Ca}$ ) should be administrated. Then, vitamin $\mathrm{D}$ deficiency should be treated if $25(\mathrm{OH}) \mathrm{D}$ is lower than $30 \mathrm{ng} / \mathrm{mL}$. If elevated PTH remains persistent over a 6-month interval, we can propose administering a low dose active oral vitamin $\mathrm{D}$ analog. In patients who are resistant to treatment regimens containing vitamin $\mathrm{D}$ analogues and calcium supplements, and phosphate binders, it might be useful to administer cinacalcet (4).

Although cinacalcet therapy of subjects on dialysis with SHPT improves clinical outcomes, especially reduces the risk of parathyroidectomy, fractures, and cardiovascular hospitalizations, there is no statistically significant reduction in the rate of mortality $(2,7)$.

Current guidelines for hemodialysis patients recommend; maintaining iPTH levels in a range which is approximately two to nine times higher than the normal limit (6). In elevated serum PTH, administration of calcitriol, vitamin $\mathrm{D}$ analogs, or calcimimetics, or a combination of these drugs will reduce serum PTH level. However, in observed patients, if hypercalcemia with serum Ca $>10.2 \mathrm{mg} / \mathrm{dL}$ and hyperphosphatemia with $\mathrm{P}>6 \mathrm{mg} / \mathrm{dL}$ occurs, calcitriol or other vitamin $\mathrm{D}$ analogs should be promptly reduced or discontinued.

Due to the presence of hypercalcemia in our patient, we stopped calcium supplementation therapy and calcitriol. Despite discontinuing calcium supplementation and calcitriol after several months, serum calcium remained

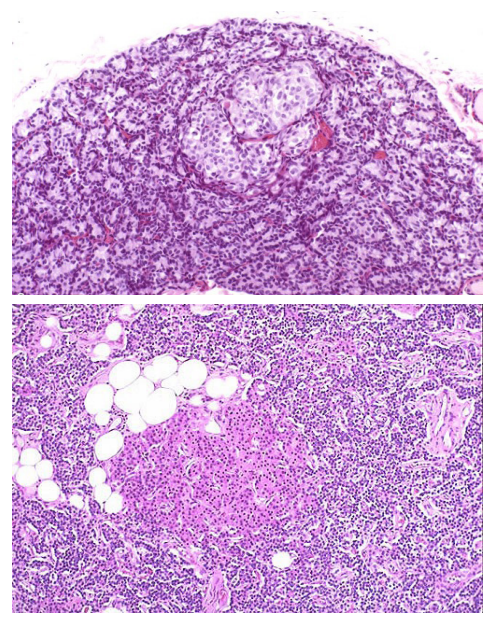

Figure 2. Nodular parathyroid hyperplasia in secondary hyperparathyroidism in ESRD patient. 
above $10 \mathrm{mg} / \mathrm{dL}$ and iPTH level did not reduce.

In patients with severe hyperparathyroidism (persistent serum levels of intact PTH $>800 \mathrm{pg} / \mathrm{mL}$ ) associated with hypercalcemia and/or hyperphosphatemia that are refractory and resistant to medical therapy NKF recommended parathyroidectomy (8). Recently a study in Japan has suggested surgical indication, when there is a high PTH level above $500 \mathrm{pg} / \mathrm{mL}$. A persistent high intact parathormone level ( $>500 \mathrm{pg} / \mathrm{mL})$, when accompanied by hypercalcemia $(>10.2 \mathrm{mg} / \mathrm{dL})$, and/or presence of high serum phosphorus levels $(>6.0 \mathrm{mg} / \mathrm{dL})$ which cannot be corrected by medical therapy, is also considered as the surgical indication for parathyroidectomy. Likewise, parathyroidectomy is indicated when parathyroid glands are expanded (volume of the biggest parathyroid gland is $>500 \mathrm{~mm}^{3}$ in ultrasonography) (5). Furthermore, individuals with high bone turnover, presence of osteitis fibrosa on X-ray, severe symptoms of secondary HPT, development of ectopic calcifications, calciphylaxis, progression of bone loss, and anemia resistant to erythropoietin therapy should definitely undergo parathyroidectomy (5). Since, there are no long-term follow up controlled studies on patients with persistent moderate hyperparathyroidism (iPTH 300-800 pg/mL), such patients are usually managed medically (5).

Our patient had persistent elevated intact PTH levels (>2000 pg/mL), accompanied by hypercalcemia $(>10.2$ $\mathrm{mg} / \mathrm{dL}$ ), that did not respond to appropriate medical therapy. Serum PTH alone is not a sufficient evidence for parathyroidectomy in asymptomatic patients, however, our case had several symptoms with extraskeletal calcification and debilitating hyper-parathyroid bone disease with multiple non-traumatic fractures that indicated parathyroidectomy was a useful modality.

\section{Conclusion}

The most important factors for stimulating parathyroid gland function in patients with kidney insufficiency are hypocalcaemia, diminished 1,25-dihydroxyvitamin D levels, and hyperphosphatemia. It seems that calcitriol therapy is effectual for managing parathormone levels (by monitoring serum calcium and phosphorus levels). While there is no sufficient evidence to justify parathyroidectomy in ESRD subjects (since there is no recent studies and randomized controlled trials in this field ), we can recommend parathyroidectomy for patients with severe SHPT (persistent serum levels of intact PTH $>800 \mathrm{pg} / \mathrm{mL}$ ), associated with severe hypercalcemia and/ or hyperphosphatemia, progressive and debilitating hyperparathyroidism bone disease, progressive extra- skeletal calcification or calciphylaxis, that are refractory and resistant to medical therapy.

Authors' contribution

$\mathrm{SD}$ and MF contributed equally to the manuscript.

\section{Conflicts of interest}

The authors report no conflicts of interest. The authors alone are responsible for the content and writing of the article.

\section{Ethical considerations}

Ethical issues (including plagiarism, data fabrication, double publication) have been completely observed by the authors.

\section{Funding/Support}

None.

\section{References}

1. Martinez I, Saracho R, Montenegro J, Llach F. The importance of dietary calcium and phosphorous in the secondary hyperparathyroidism of patients with early renal failure. Am J Kidney Dis. 1997;29:496-502.

2. Cunningham J, Danese M, Olson K, Klassen P, Chertow GM. Effects of the calcimimetic cinacalcet $\mathrm{HCl}$ on cardiovascular disease, fracture, and health-related quality of life in secondary hyperparathyroidism. Kidney Int. 2005;68:1793-800.

3. Block GA, Martin KJ, De Francisco AL, Turner SA, Avram MM, Suranyi MG, et al. Cinacalcet for secondary hyperparathyroidism in patients receiving hemodialysis. N Engl J Med. 2004;350:1516-25.

4. Verheyen N, Pilz S, Eller K, Kienreich K, Fahrleitner-Pammer A, Pieske B, et al. Cinacalcet hydrochloride for the treatment of hyperparathyroidism. Expert Opin Pharmacother. 2013;14:793-806.

5. Tominaga Y, Matsuoka S, Sato T. Surgical indications and procedures of parathyroidectomy in patients with chronic kidney disease. Therapeutic apheresis and dialysis. 2005;9:447.

6. Moe S. Kidney disease: improving global outcomes (KDIGO). Definition, evaluation, and classification of renal osteodystrophy: a position statement from Kidney Disease: Improving Global Outcomes (KDIGO). Kidney Int. 2006;69:1945-53.

7. EVOLVE Trial Investigators, Chertow GM, Block GA, CorreaRotter R, Drüeke TB, Floege J, et al. Effect of cinacalcet on cardiovascular disease in patients undergoing dialysis. N Engl J Med. 2012;367:2482-94.

8. Johnson CA, Levey AS, Coresh J, Levin A, Lau J, Eknoyan G. Clinical practice guidelines for chronic kidney disease in adults: Part I. Definition, disease stages, evaluation, treatment, and risk factors. Am Fam Physician. 2004;70:869-76. 